\title{
Imprinting dimples on narrowly dispersed polymeric spheres by heterocoagulation between hard polymer particles and soft oil droplets
}

Kanji Kadowaki, Haruyuki Ishii, Daisuke Nagao, * Mikio Konno

Department of Chemical Engineering, Tohoku University

6-6-07 Aoba, Aramaki-aza Aoba-ku, Sendai, 980-8579 (Japan)

E-mail: dnagao@tohoku.ac.jp

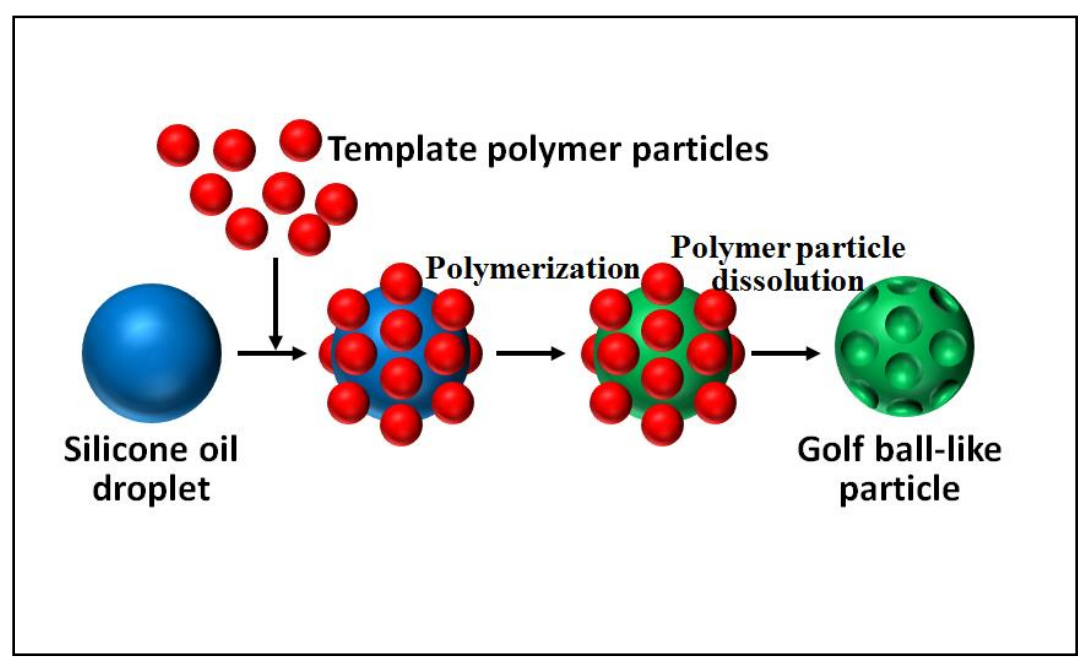



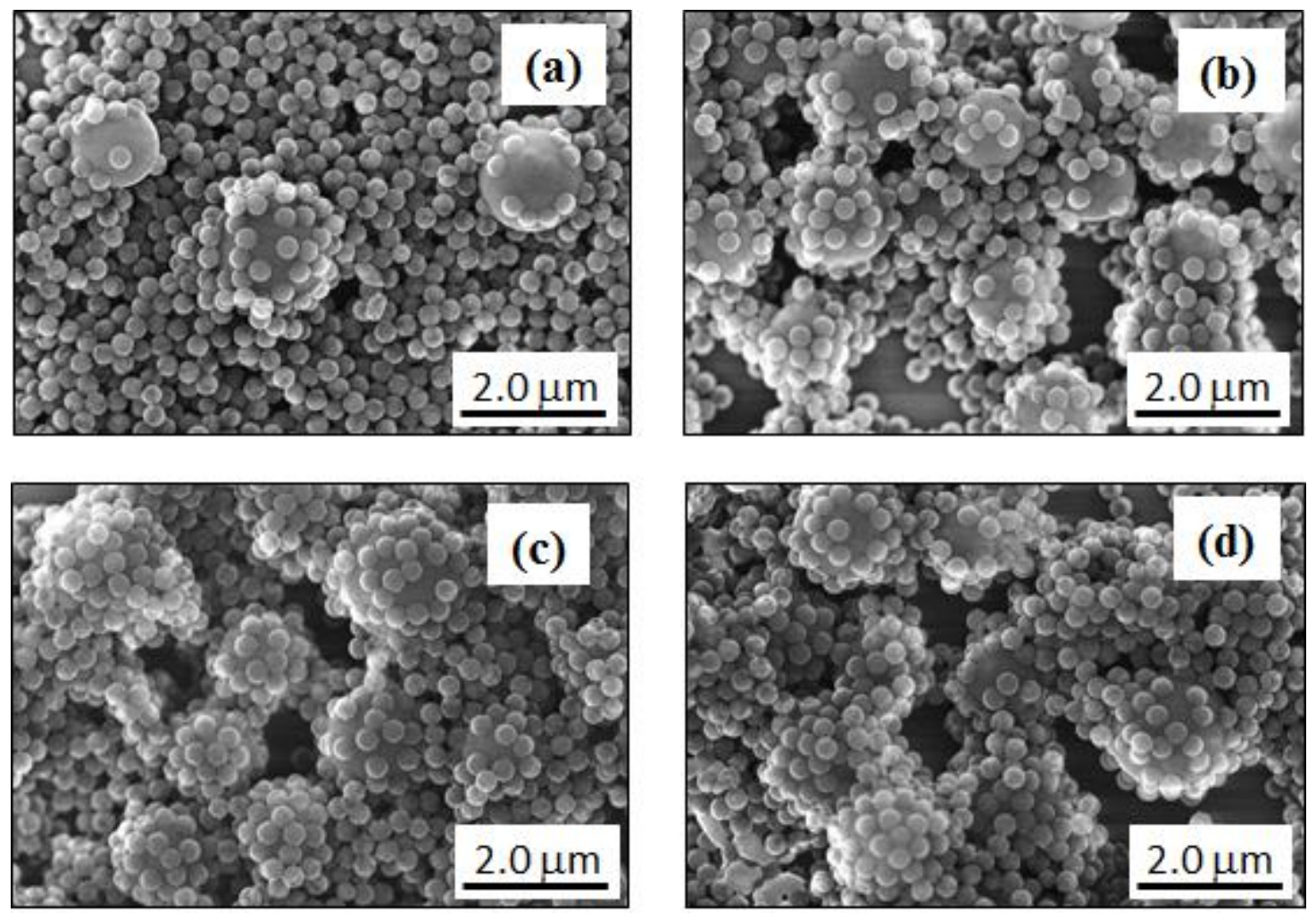

Figure S1 SEM images of particles formed by the heterocoagulations at different $\mathrm{HCl}$ concentrations of 30(a), 35(b), 40(c) and $45 \mathrm{mM}(\mathrm{d})$. 


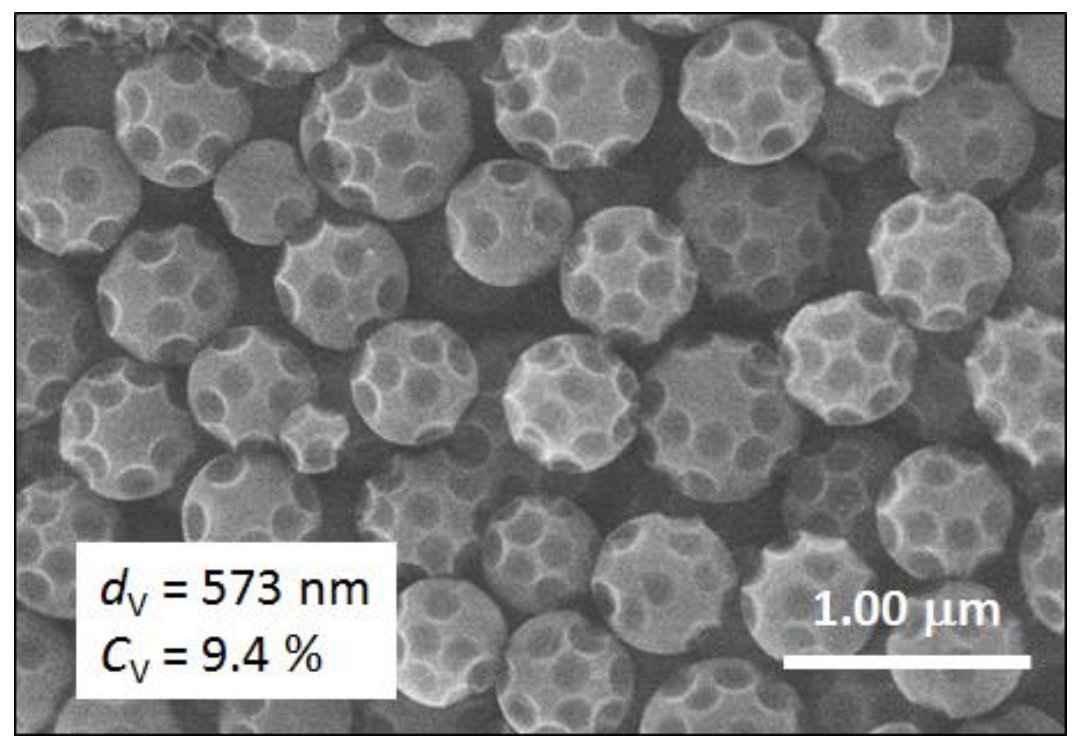

Figure S2 SEM image of golf ball-like particles obtained by heat treatment at $500^{\circ} \mathrm{C}$ for $3 \mathrm{~h}$. The number ratio of PSt particles to oil droplets was 100 in the heterocoagulation.

(a) PMMA particles

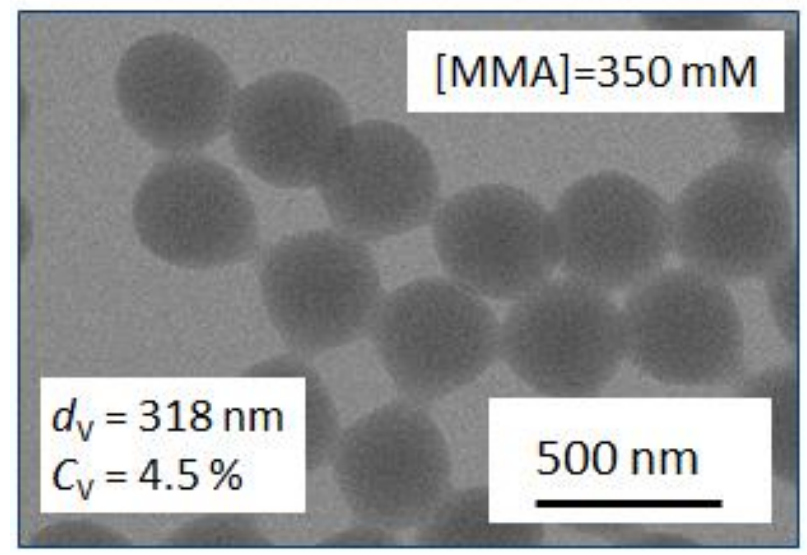

(b) $\mathbf{P S t}_{\text {SDBS }}$

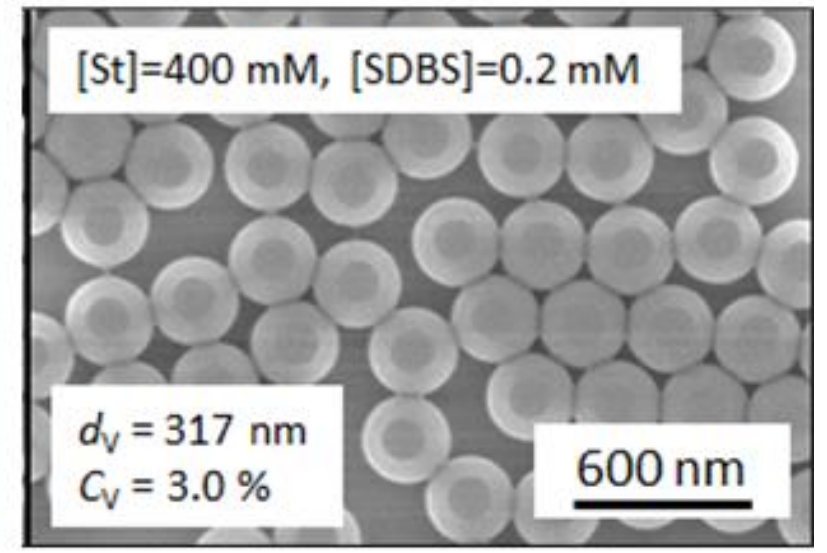

Figure S3 EM images of PMMA particles (a) and PSt particles (b) prepred in soap-free emulsion polymerization in the absence and presence of sodium dodecyl benzene sulfonate (SDBS). 


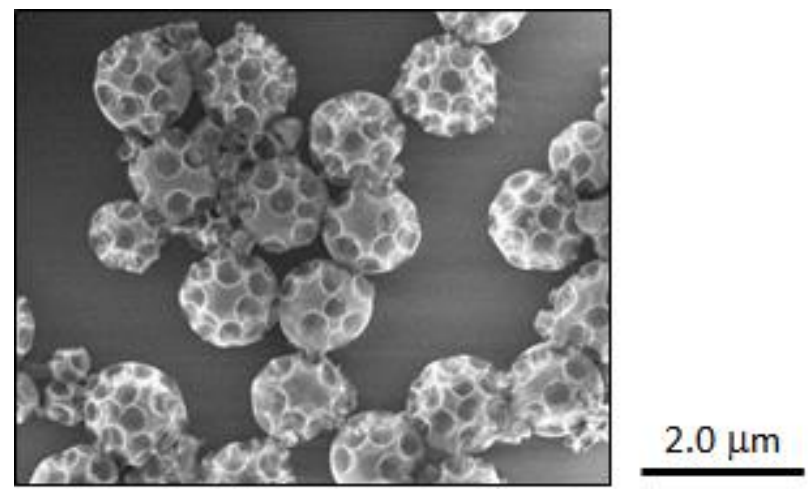

Figure S4 SEM image of typical golf ball-like particles formed with PMMA particles.

Table S1 Comparison on zeta-potentials of PSt particles with different sizes at pH 2

\begin{tabular}{|l|c|c|}
\hline & $\begin{array}{c}\text { Average diameter } \\
{[\mathrm{nm}]}\end{array}$ & $\begin{array}{c}\text { Zeta potential } \\
{[\mathrm{mV}]}\end{array}$ \\
\hline Small & 213 & 40 \\
\hline Middle & 307 & 56 \\
\hline Large & 602 & 62 \\
\hline
\end{tabular}

Table S2 Comparison on dimensions of golf ball-like particles prepared with different particles.

\begin{tabular}{|l|c|c|c|c|}
\hline & $\begin{array}{c}\text { Particle } \\
\text { diameter }[\mathrm{nm}]\end{array}$ & $\begin{array}{c}\text { Dimple diameter } \\
\text { measured }[\mathrm{nm}]\end{array}$ & $\begin{array}{c}\text { Dimple depth } \\
\text { calculated [nm] }\end{array}$ & $\begin{array}{c}\text { Contact angle } \\
\text { calculated [deg] }\end{array}$ \\
\hline PMMA & 316 & $315\left(C_{V}=8.0 \%\right)$ & 145 & 95 \\
\hline PSt $_{\text {SDBS }}$ & 317 & $200\left(C_{V}=13.4 \%\right)$ & 36 & 141 \\
\hline
\end{tabular}

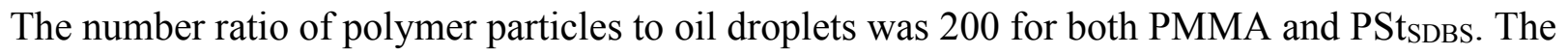
concentration of $\mathrm{HCl}$ was $40 \mathrm{mM}$ in the heterocoagulations. 